\title{
Yeast-Leavened Laminated Salty Baked Goods: Flour and Dough Properties and Their Relationship with Product Technological Quality
}

\author{
Ana E. de la Horra, María Eugenia Steffolani, Gabriela N. Barrera, Pablo D. Ribotta \\ and Alberto E. León* \\ Faculty of Agricultural Sciences, National University of Cordoba (UNC), \\ Institute of Food Science and Technology of Córdoba (ICYTAC), \\ CONICET-UNC Valparaiso and Rogelio Martínez Avenue, 5000 Córdoba, Argentina
}

Received: March 13, 2015

Accepted: May 13, 2015

\begin{abstract}
Summary
The effect of protein composition and content on the characteristics and properties of laminated baked products has been studied for a long time. However, there are no flour quality parameters related to its suitability to produce yeast-leavened laminated salty baked products. The relationships among flour characteristics, laminated dough pieces and baked products were studied in order to establish flour quality parameters and help predict the quality of the products. Yeast-leavened salty laminated products made with hard wheat flour had better quality properties than the products made with soft wheat flour. Hydrophilic components and a high gluten network quality are responsible for the generation of a rigid structure and viscous dough. Consequently, during baking, the dough rises rather than extends laterally and does not experience any change in the expected shape. Among the analysed flour characteristics, glutenin macropolymer content, lactic acid and sodium carbonate solvent retention capacities together with dough viscosity and resistance to deformation were the variables which influenced the most the quality of yeast-leavened salty laminated products.
\end{abstract}

Key words: laminated baked product, laminated dough, wheat flour quality parameters, stress relaxation

\section{Introduction}

Puff and Danish pastries are among the most common baked products involving an interleaving of thin layers of fat and dough sheets in their preparation. Puff pastry is made by layering shortening with tough but pliable dough in a similar way to Danish pastry (1). Dough expansion depends largely on the ability of dough layers to remain separate and discrete from fat layers, although other factors also contribute, to some extent, to the product lifting. In unleavened puff pastry, water is held in dough layers and, when converted to steam, is trapped in the melting fat between the dough layers, producing the lifting. Consequently, in sweet Danish pastry, a very open network of crispy and flaky layers is formed and the presence of yeast generates a relatively soft and porous structure in the baked dough layers (2).

The suitability of flour to obtain puff and Danish pastries has been reported, e.g. Cauvain and Young (2) and Matzs (3) affirmed that the use of too strong flour can cause excessive shrinking of puff pastry products. Strong types of flour require longer resting periods than weak flour in order for the dough rheology to become optimised for sheeting and laminating. Matzs (3) found an improvement in Danish pastry quality when 15 or $20 \%$ of 
hard flour was replaced by soft wheat flour. Davies et al. (4) studied the structure and functionality of proteins in pastry dough before and during the baking process and they found that high quality pastry flour is able to form thin dough laminates $(30 \mu \mathrm{m})$, while the flour of inferior quality formed thicker and less well-defined sheets. In 1989, Zabik and Tipton (5) evaluated the influence of quantity and quality of the gluten of soft wheat flour on textural characteristics of pastry. Positive correlations were found between gluten quantity and flakiness and crust shrinkage, while surface blistering score and breaking strength decreased as the gluten quantity decreased. Hay (6) found that specific puff pastry height increased with increasing protein content. In a similar way, the specific puff pastry volume had positive correlations with protein content high molecular mass, low molecular mass and quantity of dough strength-related high-molecular mass glutenin subunit.

Although considerable efforts have been made to establish flour quality parameters that can be used to reliably predict puff and Danish pastry product quality, the objective has been partially fulfilled. Geittner (7) recommended the Brabender extensogram as a quality parameter and proposed a range between 80 and $110 \mathrm{~cm}^{2}$. Hay (6) identified dough properties (tension energy and water absorption) as the best predictors of specific puff pastry height and volume. On the other hand, Hay (6) also studied the relationships between pastry quality parameters and bread. However, bread baking performance cannot be used as an indicator of the baking quality of a pastry, and the models developed to predict loaf volume from protein components of flour do not hold in this context. Morgenstern et al. (8) argued that pastry dough is different from bread dough, not only in composition but also in the strains and strain rates that are applied during pastry making. Therefore, against some existing tedious methods untranslated into fundamental rheology properties, they proposed a quick and easy method to measure extensional properties of sheeted dough pieces. However, the issue of establishing flour quality parameters to help predict the quality of laminated bakery products in order to obtain products with similar and uniform characteristics over time is still unresolved. Therefore, the study of yeast-leavened laminated salty products will contribute to the scientific knowledge about laminated systems and its industrialization in countries where laminated baked goods are among the most consumed products (9).

The yeast-leavened laminated salty products share some characteristics with puff and Danish pastries. However, the simultaneous presence of salt and yeast in a laminated system affects flour quality requirements, dough behaviour during sheeting, fermentation and baking stages and final quality of the product in different ways. The yeast plays a significant part in the aeration of the dough during fermentation and baking, and it also disrupts the integrity of the dough layers and fat layers (2).

In this context, the aim of our work is to establish flour and dough quality parameters to help predict the quality of a yeast-leavened laminated salty product. The relationships between flour characteristics, laminated dough pieces and baked products were studied.

\section{Materials and Methods}

\section{Materials}

Wheat samples from the 2011 Argentinian bulk harvest were provided by the Experimental Research Station Marcos Juárez of the National Institute of Agricultural and Fishing Technology (INTA), Buenos Aires, Argentina. Three experimental soft wheat cultivars (Triticum aestivum (L.) Thell. ssp. compactum (Host) MacKey) were used: JTB 2 (Sw1), JTB 10 (Sw2) and JTB 31 (Sw3), and six hard wheat cultivars (Triticum aestivum (L.) Thell. ssp. aestivum): Baguette Premium 11 (Hw4), Klein Proteo (Hw5), BIOINTA 3004 (Hw6), Klein Tauro (Hw7), Klein Yarara (Hw8) and BIOINTA 1005 (Hw9) were used to make laminated baked products. The wheat samples were conditioned to $14.5 \%$ moisture and milled with a Bühler SA MLU 202 laboratory mill (Bühler SA, Buenos Aires, Argentina). Commercial lard (La Cordobesa, Cordoba, Argentina), made from refined bovine fat, and oleomargarine were used in the formulation (melting point: $(46.94 \pm 0.08){ }^{\circ} \mathrm{C}$, solid fat index at 10, 15, 20, 25, 30 and $40{ }^{\circ} \mathrm{C}: 54.0,51.4,46.2,38.9$, 31.4 and $17.8 \%$, respectively).

\section{Flour characterisation}

Total proteins were determined following the AACC International method 46-10.01 (10). Wet gluten was obtained by the hand washing method following the AACC International method 38-10.01 (11). The glutenin macropolymer was isolated according to Don et al. (12) and its protein content was determined by the AACC International Kjeldahl method 46-13.01 (13). Results were expressed in $\mathrm{g}$ of glutenin macropolymer per $100 \mathrm{~g}$ of flour.

Solvent retention capacity (SRC) profile was obtained according to the AACC International method 56-11.02 (14). Flour samples ( $5 \mathrm{~g}$ ) were suspended with $25 \mathrm{~g}$ of water, $50 \%$ sucrose, $5 \%$ sodium carbonate, and $5 \%$ lactic acid. The samples were hydrated for $20 \mathrm{~min}$ and centrifuged at $1000 \times g$ for $15 \mathrm{~min}$. Each obtained precipitate was weighed and the SRC of each sample was calculated according to the AACC International method (14).

Sodium dodecyl sulphate sedimentation index was determined following the AACC International method 56-70.01 (15), measuring the volume $\left(\mathrm{cm}^{3}\right)$ obtained from $1 \mathrm{~g}$ of flour suspended with $12 \mathrm{~mL}$ of sodium dodecyl sulphate reagent and submitted to shaking and resting periods. Each test was performed at least in duplicate.

\section{Elaboration of a yeast-leavened laminated salty product}

The dough was prepared from $100 \mathrm{~g}$ of wheat flour, $20 \mathrm{~g}$ of lard, $2.8 \mathrm{~g}$ of compressed yeast, $2.5 \mathrm{~g}$ of salt, $1.4 \mathrm{~g}$ of sugar and $50 \mathrm{~mL}$ of water. The ingredients were mixed for $3 \mathrm{~min}$ in a mixer (MPZ Pedro Zambón e hijos, Córdoba, Argentina), until the dough was obtained. A mass of $33.3 \mathrm{~g}$ of lard was envelope-folded into a dough sheet and then gauged to $60 \mathrm{~mm}$ thickness in six steps, using a sheeter (MA-AR Acrilic, S.R.L., Córdoba, Argentina). The dough was given a twofold turn and allowed to rest for 20 min at $23{ }^{\circ} \mathrm{C}$; then it was gauged to $50 \mathrm{~mm}$ thickness in seven steps and given another twofold turn. It was then allowed to rest for 20 more min and gauged to a thickness 
of $50 \mathrm{~mm}$. The dough was laminated via a two-fold turn and the final gauging was to about $150 \mathrm{~mm}$ thickness. Circular perforations (diameter $d=2 \mathrm{~mm}$ ) of $1.6 \mathrm{~cm}$ each were done on the dough to avoid the complete separation of layers during baking. Square dough pieces $(5 \mathrm{~cm} \times 5$ $\mathrm{cm} \times 1.5 \mathrm{~cm}$ ) were fermented at $35^{\circ} \mathrm{C}$ and $80 \%$ relative humidity, until they duplicated their height. They were baked at $175{ }^{\circ} \mathrm{C}$ for $27 \mathrm{~min}$ in a Beta 107 IPA convector oven (Pauna, Córdoba, Argentina). Three products of each sample were produced and the procedure was repeated at least twice.

\section{Baked product quality parameters}

The conformational change of the dough pieces during the production process was evaluated. The dimensions (height, width and length) of the dough pieces at the beginning of fermentation and of the baked products after cooling for $1 \mathrm{~h}$ were measured. The height and width ratios of baked vs. unfermented dough were calculated. The shape factor (SF) of the baked products was calculated as follows:

$$
\mathrm{SF}=\frac{\text { height }}{\frac{\text { width+length }}{2}}
$$

The product volume was determined by rapeseed displacement after cooling for $1 \mathrm{~h}$. The specific volume was expressed as the volume per mass ratio of the final product. A piece of crumb of $20 \mathrm{~mm}$ thickness, previously cut in a longitudinal direction, was compressed to $40 \%$ of its initial height using a cylindrical probe $(d=2.5 \mathrm{~cm})$ in the Instron 3342 (Norwood, MA, USA) texture analyser. Force deformation curves were obtained at a crosshead speed of $1 \mathrm{~mm} / \mathrm{s}$. Crumb firmness was defined as the maximum force registered and was expressed in Newton (N). Crust firmness was determined directly on the baked product, under the same conditions mentioned before and expressed in N. Three products of each sample were tested and each measurement was performed at least in duplicate. The determinations were carried out on baked products after cooling for $1 \mathrm{~h}$.

\section{Dough quality parameters}

A stress relaxation test was done using the Instron 3342 texture analyzer (Norwood). Cylindrical pieces of nonfermented laminated dough prepared as described above were compressed with a cylindrical probe $(d=5.0$ $\mathrm{cm})$, at $0.5 \mathrm{~mm} / \mathrm{s}$ speed up to $30 \%$ of its initial height and maintained compressed for $2 \mathrm{~min}$. The force was recorded as a function of time and the relaxation curves were fitted with the following equations:

$$
\begin{gathered}
\mathrm{s}(t)=E_{1} e^{\left(\frac{-t}{t_{\mathrm{r}}}\right)}+\varepsilon_{0} \\
t_{\mathrm{r}}=\frac{\eta}{E_{1}}
\end{gathered}
$$

This expression corresponds to a Maxwell element in parallel with a spring (16), where $\sigma$ is the stress, $E_{1}$ is the elastic modulus, $\varepsilon_{0}$ is the equilibrium elastic modulus and $t_{\mathrm{r}}$ is the relaxation time, which is defined by Eq. 3, where the viscosity $(\eta)$ and $E_{1}$ are related.

A piece of nonfermented laminated dough prepared as described above was compressed up to $40 \%$ of its ini- tial height, using a cylindrical probe $(d=2.5 \mathrm{~cm})$. Force deformation curves were obtained at a crosshead speed of 1 $\mathrm{mm} / \mathrm{s}$. Dough resistance to deformation was defined as the maximum force registered. Three dough pieces of each sample were tested and each test was performed at room temperature $\left(25^{\circ} \mathrm{C}\right)$ and at least in duplicate.

\section{Statistical analysis}

The experimental determinations were done at least in duplicate and compared by the analysis of variance (ANOVA), using the Di Rienzo, Guzmán and Casanoves test (DGC), where the relationship between the measured parameters was assessed by Pearson's test (significant level at $\mathrm{p} \leq 0.05)$ (17). A multivariate analysis of variance (MANOVA; InfoStat statistical software, Faculty of Agricultural Sciences, UNC, Córdoba, Argentina) was used in order to analyse global differences between the samples considering more than one variable. To compare the multivariable hypothesis, the Hotelling method was used (significant level at $\mathrm{p} \leq 0.05$ ).

\section{Results and Discussion}

\section{Characteristics of flour samples}

Samples 1 and 2 of soft wheat flour had the lowest protein values, while soft wheat flour sample 3 and all samples of hard wheat flour had higher protein content (Table 1). Sliwinsky et al. (18) related the differences in flour baking performance with puff pastry dough rheological properties using the flour with a protein content in the range of $10.3-13.5 \%$. Sample 1 of soft wheat flour also had the lowest wet gluten content, followed by soft wheat flour sample 2, and hard wheat flour samples 6 and 8 . Hard wheat flour samples 4 and 9 had intermediate wet gluten percentages. Soft wheat flour sample 3 and hard wheat flour samples 5 and 7 had wet gluten values higher than $37 \%$ (Table 1). Soft wheat flour sample 2 had the lowest glutenin macropolymer mass fraction, followed by soft wheat flour samples 1 and 3. Flour from hard wheat had higher glutenin macropolymer content than soft wheat flour samples, with the highest mass fraction in hard wheat flour sample 5 (Table 1). Don et al. (19) and Steffolani et al. (20) found similar glutenin macropolymer values in hard wheat flour samples (0.5-3.6 and 2.0-3.3\%, respectively).

Lactic acid SRC values (Table 1) were in general higher than $115 \%$ in hard wheat samples, except for hard wheat sample 6, while soft wheat flour samples had lower lactic acid SRC values. This tendency allowed us to associate hard wheat flour samples with a high glutenin network quality, and consequently with a high relative strength (21). Moiraghi et al. (22) reported a similar range of lactic acid SRC values in Argentinian hard wheat flour (99.9-121.0 \%). Hard wheat flour samples had sucrose SRC values greater than $90 \%$, while soft wheat flour samples had lower percentages. These results suggest that hard wheat flour samples had a high content of pentosan and gliadin. The observed values are in agreement with those of Colombo et al. (23) and Xiao et al. (24), who registered sucrose SRC values greater than $95.11 \%$ in Argen- 
Table 1 . Flour quality parameters and predictive tests

\begin{tabular}{ccccccccc}
\hline & & & \multicolumn{5}{c}{ SRC/\% } \\
\cline { 5 - 7 } Sample & $w$ (protein)/\% & $w$ (WG)/\% & $w$ (GMP)/\% & Lactic acid & Sucrose & $\begin{array}{c}\text { Sodium } \\
\text { carbonate }\end{array}$ & Water & $V_{\mathrm{s}} / \mathrm{mL}$ \\
\hline Sw1 & $(9.2 \pm 0.1)^{\mathrm{a}}$ & $(26.5 \pm 0.4)^{\mathrm{a}}$ & $(2.5 \pm 0.4)^{\mathrm{b}}$ & $(115.0 \pm 2.0)^{\mathrm{d}}$ & $(83.3 \pm 0.6)^{\mathrm{c}}$ & $(76.4 \pm 3.1)^{\mathrm{a}}$ & $(53.8 \pm 0.4)^{\mathrm{a}}$ & $(14.0 \pm 0.0)^{\mathrm{c}}$ \\
Sw2 & $(9.2 \pm 0.4)^{\mathrm{a}}$ & $(30.2 \pm 0.5)^{\mathrm{b}}$ & $(1.4 \pm 0.4)^{\mathrm{a}}$ & $(77.4 \pm 0.5)^{\mathrm{a}}$ & $(73.6 \pm 0.1)^{\mathrm{b}}$ & $(69.6 \pm 0.4)^{\mathrm{a}}$ & $(51.3 \pm 1.4)^{\mathrm{a}}$ & $(10.0 \pm 0.7)^{\mathrm{a}}$ \\
Sw3 & $(10.6 \pm 0.4)^{\mathrm{b}}$ & $(37.2 \pm 0.5)^{\mathrm{d}}$ & $(2.5 \pm 0.1)^{\mathrm{b}}$ & $(91.2 \pm 3.3)^{\mathrm{b}}$ & $(58.9 \pm 2.6)^{\mathrm{a}}$ & $(71.9 \pm 1.3)^{\mathrm{a}}$ & $(52.4 \pm 1.4)^{\mathrm{a}}$ & $(11.7 \pm 0.3)^{\mathrm{b}}$ \\
Hw4 & $(10.3 \pm 0.2)^{\mathrm{b}}$ & $(33.6 \pm 0.6)^{\mathrm{c}}$ & $(3.4 \pm 0.5)^{\mathrm{c}}$ & $(124.6 \pm 0.9)^{\mathrm{e}}$ & $(90.6 \pm 0.3)^{\mathrm{d}}$ & $(83.0 \pm 1.8)^{\mathrm{b}}$ & $(67.4 \pm 0.5)^{\mathrm{c}}$ & $(17.0 \pm 0.0)^{\mathrm{d}}$ \\
Hw5 & $(14.8 \pm 0.4)^{\mathrm{d}}$ & $(47.3 \pm 0.5)^{\mathrm{f}}$ & $(4.5 \pm 0.5)^{\mathrm{d}}$ & $(154.2 \pm 3.8)^{\mathrm{g}}$ & $(92.9 \pm 4.1)^{\mathrm{d}}$ & $(86.4 \pm 1.1)^{\mathrm{b}}$ & $(67.4 \pm 1.1)^{\mathrm{c}}$ & $(18.2 \pm 0.3)^{\mathrm{e}}$ \\
Hw6 & $(10.36 \pm 0.07)^{\mathrm{b}}$ & $(31.1 \pm 0.2)^{\mathrm{b}}$ & $(3.3 \pm 0.1)^{\mathrm{c}}$ & $(92.1 \pm 1.5)^{\mathrm{b}}$ & $(94.5 \pm 1.8)^{\mathrm{d}}$ & $(87.1 \pm 2.5)^{\mathrm{b}}$ & $(66.3 \pm 1.9)^{\mathrm{c}}$ & $(13.5 \pm 0.0)^{\mathrm{c}}$ \\
Hw7 & $(13.2 \pm 0.0)^{\mathrm{c}}$ & $(41.12 \pm 0.04)^{\mathrm{e}}$ & $(3.8 \pm 0.2)^{\mathrm{c}}$ & $(115.2 \pm 2.1)^{\mathrm{d}}$ & $(96.3 \pm 0.2)^{\mathrm{d}}$ & $(87.8 \pm 1.8)^{\mathrm{b}}$ & $(69.30 \pm 0.03)^{\mathrm{c}}$ & $(18.0 \pm 0.0)^{\mathrm{e}}$ \\
Hw8 & $(11.1 \pm 0.1)^{\mathrm{b}}$ & $(31.4 \pm 0.9)^{\mathrm{b}}$ & $(3.8 \pm 0.0)^{\mathrm{c}}$ & $(145.2 \pm 0.6)^{\mathrm{f}}$ & $(92.1 \pm 0.2)^{\mathrm{d}}$ & $(82.53 \pm 0.07)^{\mathrm{b}}$ & $(63.1 \pm 0.9)^{\mathrm{b}}$ & $(19.0 \pm 0.0)^{\mathrm{f}}$ \\
Hw9 & $(11.3 \pm 0.3)^{\mathrm{b}}$ & $(34.3 \pm 0.2)^{\mathrm{c}}$ & $(3.5 \pm 0.5)^{\mathrm{c}}$ & $(108.6 \pm 0.5)^{\mathrm{c}}$ & $(90.7 \pm 0.3)^{\mathrm{d}}$ & $(85.1 \pm 4.5)^{\mathrm{b}}$ & $(66.4 \pm 1.2)^{\mathrm{c}}$ & $(17.5 \pm 0.0)^{\mathrm{d}}$ \\
\hline
\end{tabular}

$\mathrm{Sw}=$ soft wheat flour, $\mathrm{Hw}=$ hard wheat flour, $\mathrm{WG}=$ wet gluten, $\mathrm{GMP}=$ glutenin macropolymer, $\mathrm{SRC}=$ solvent retention capacity, $V_{\mathrm{s}}=$ sodium dodecyl sulphate sedimentation volume. Values are on a $14 \%$ moisture basis. Determinations were done at least in duplicate. Values followed by a different letter are significantly different $(\mathrm{p} \leq 0.05)$

tinian hard wheat and hard red winter wheat flour from the USA, respectively. The sodium carbonate SRC values of soft wheat flour were lower than of hard wheat samples, showing that hard wheat flour had a higher level of damaged starch. This could be attributed to the greater force applied to the grains of hard wheat during the milling process (24). The hard wheat samples had higher values of water SRC, indicating their great ability to hold water (24). Soft wheat flour had similar water SRC values to those of Argentinian soft wheat samples determined by Moiraghi et al. (25). Hard wheat flour had the highest sodium dodecyl sulphate sedimentation volume, which revealed strong capacity to form a protein network, necessary to retain the gas during fermentation. These results are in agreement with those of Colombo et al. (23) for Argentinian hard wheat samples (11.75-19.25\%). On the other hand, hard wheat flour sample 6 and soft wheat flour samples had the lowest sodium dodecyl sulphate sedimentation volume. There was a great variability among the studied samples which allowed us to evaluate the relationships among flour characteristics, laminated dough pieces and baked products.

\section{Dough properties}

Dough samples made with hard wheat flour showed different stress relaxation characteristics from samples made with soft wheat flour (Table 2). Dough samples 7, 8 and 9 made with hard wheat flour had the highest elastic modulus $\left(E_{1}\right)$ values, which could be associated with stiff dough samples (26). At the equilibrium, hard wheat dough samples had higher elastic modulus $\left(\varepsilon_{0}\right)$ values than soft wheat dough samples. Characteristic relaxation time $\left(t_{\mathrm{r}}\right)$, considered a discriminator of strength (27), of dough samples made with hard wheat flour and soft wheat flour sample 3 was higher, revealing a stronger solid-like behaviour (16). Dough samples 1 and 2 made with soft wheat flour had lower values of $t_{\mathrm{r}}$, related to a fast relaxation of the system. Li et al. (28) found that dough and gluten from English strong flour had higher relaxation modulus and relaxation intensity than those with weak flour over the whole relaxation time in a fundamental rheology test. They suggested that differences in the relaxation behaviour between flour types with different baking quality were related to the gluten network structure. Dough and gluten from strong flour had a strong network, which may be attributed to the protein molecular entanglements and physical cross-links. The lower values of viscosity $(\eta)$ of dough samples made with soft wheat flour indicate a higher capacity to flow than the samples made with hard wheat flour.

Table 2. Laminated dough stress relaxation parameters

\begin{tabular}{ccccc}
\hline Sample & $\varepsilon_{0}$ & $E_{1} / \mathrm{kPa}$ & $t_{\mathrm{r}} / \mathrm{s}$ & $\eta /(\mathrm{kPa} \cdot \mathrm{s})$ \\
\hline Sw1 & $(5.4 \pm 0.8)^{\mathrm{a}}$ & $(9.3 \pm 1.8)^{\mathrm{a}}$ & $(7.1 \pm 0.5)^{\mathrm{a}}$ & $(97.1 \pm 5.9)^{\mathrm{a}}$ \\
Sw2 & $(6.8 \pm 1.0)^{\mathrm{a}}$ & $(17.4 \pm 2.1)^{\mathrm{b}}$ & $(7.1 \pm 0.3)^{\mathrm{a}}$ & $(94.1 \pm 8.8)^{\mathrm{a}}$ \\
Sw3 & $(5.9 \pm 0.3)^{\mathrm{a}}$ & $(18.7 \pm 2.4)^{\mathrm{b}}$ & $(9.1 \pm 0.2)^{\mathrm{b}}$ & $(133.4 \pm 10.6)^{\mathrm{b}}$ \\
Hw4 & $(14.7 \pm 2.5)^{\mathrm{b}}$ & $(20.4 \pm 2.7)^{\mathrm{b}}$ & $(9.2 \pm 0.7)^{\mathrm{b}}$ & $(148.6 \pm 11.1)^{\mathrm{c}}$ \\
Hw5 & $(11.5 \pm 0.8)^{\mathrm{b}}$ & $(19.2 \pm 0.4)^{\mathrm{b}}$ & $(10.3 \pm 0.6)^{\mathrm{c}}$ & $(203.3 \pm 12.1)^{\mathrm{c}}$ \\
Hw6 & $(14.43 \pm 0.03)^{\mathrm{b}}$ & $(21.7 \pm 0.2)^{\mathrm{b}}$ & $(9.0 \pm 0.8)^{\mathrm{b}}$ & $(179.3 \pm 10.6)^{\mathrm{c}}$ \\
Hw7 & $(36.4 \pm 2.7)^{\mathrm{c}}$ & $(25.5 \pm 2.7)^{\mathrm{c}}$ & $(8.7 \pm 0.7)^{\mathrm{b}}$ & $(201.6 \pm 1.2)^{\mathrm{c}}$ \\
Hw8 & $(44.1 \pm 0.3)^{\mathrm{c}}$ & $(26.9 \pm 2.4)^{\mathrm{c}}$ & $(8.4 \pm 0.5)^{\mathrm{b}}$ & $(197.5 \pm 21.1)^{\mathrm{c}}$ \\
Hw9 & $(37.5 \pm 2.4)^{\mathrm{c}}$ & $(25.4 \pm 4.0)^{\mathrm{c}}$ & $(8.32 \pm 0.03)^{\mathrm{b}}$ & $(194.6 \pm 12.0)^{\mathrm{c}}$ \\
\hline
\end{tabular}

$\mathrm{Sw}=$ laminated dough made with soft wheat flour, $\mathrm{Hw}=$ laminated dough made with hard wheat flour, $\varepsilon_{0}=$ equilibrium elastic modulus, $E_{1}=$ elastic modulus, $t_{\mathrm{r}}=$ relaxation time, $\eta=$ viscosity. Determinations were done at least in duplicate. Values followed by a different letter are significantly different $(p \leq 0.05)$

Samples of the dough made with soft wheat flour had values of resistance to deformation lower than $10 \mathrm{~N}$ (Fig. 1 ), while samples of the dough made with hard wheat flour were harder, which is associated with higher values of resistance to deformation. Positive and significant correlation between resistance to deformation and $\eta(\mathrm{R}=0.72$; $\mathrm{p} \leq 0.05)$ suggested that samples of hard dough were more viscous. 


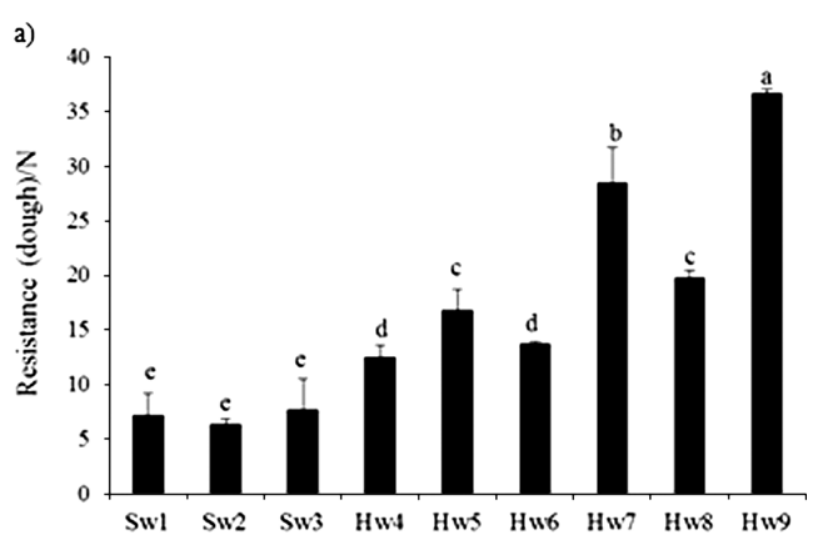

b)

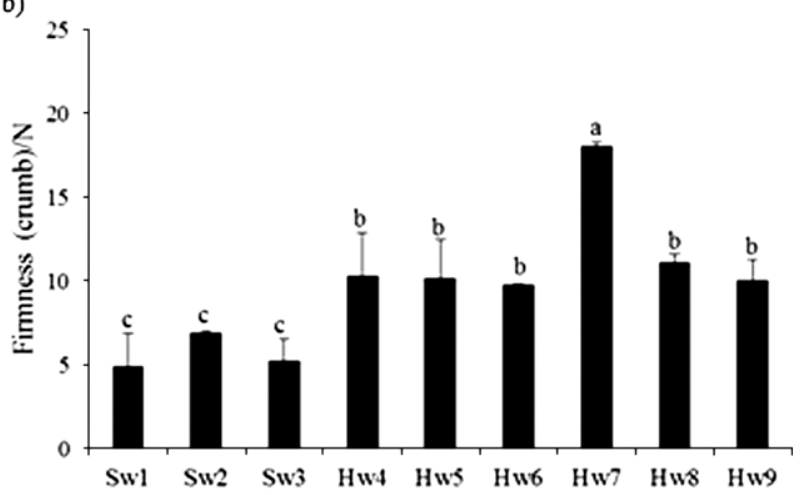

c)

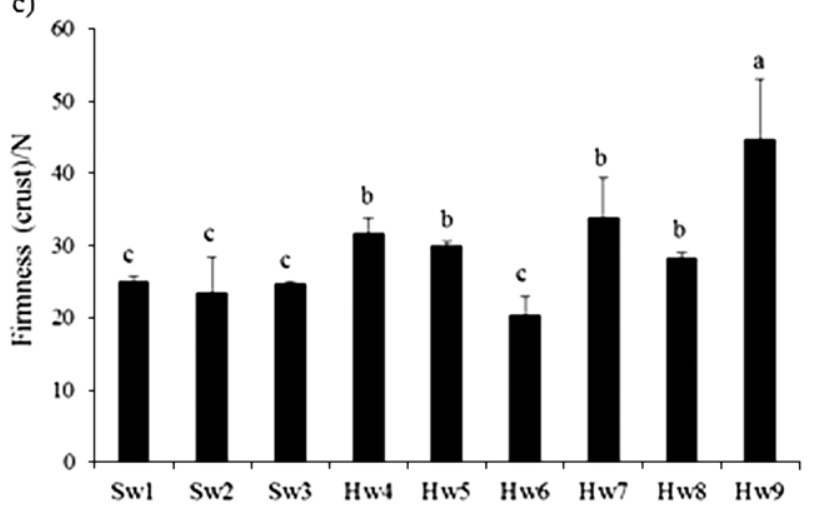

Fig. 1. Textural parameters of the dough and yeast-leavened laminated salty product: a) dough resistance to deformation, b) baked product crumb firmness, c) baked product crust firmness. Determinations were done at least in duplicate. Columns with a different letter are significantly different $(\mathrm{p} \leq 0.05)$. Sw=soft wheat flour samples, $\mathrm{Hw}=$ hard wheat flour samples

\section{Properties of yeast-leavened laminated baked product}

Yeast-leavened laminated baked products were prepared (Fig. 2) using soft and hard wheat flour. The lateral view of the products made with hard wheat flour revealed sheeted structure with thin layers aligned horizontally. On the other hand, products made with soft wheat flour had a disrupted structure where layers seemed to be merged, forming a coarse and uneven strata.

In yeast-leavened laminated products the desired expansion is an upward growth, during which the dough maintains its symmetry without excessive lateral growth. In this study a shape factor, which reflects the dimensions of a baked product, was considered. The shape factor values (Table 3) for products made with hard wheat flour were higher, revealing a greater height and smaller width and length than the products made with soft wheat flour. Soft wheat flour products had higher values of width ratio than hard wheat flour products, while products made with hard wheat flour samples 4 and 5 had the highest height ratio (Table 3). Most samples did not exhibit a significant difference in their specific volumes, except for the hard wheat flour product 6, which had the highest value. Hay (6) found that a high quality puff pastry had a high specific volume. However, in yeast-leavened laminated products the specific volume was not a parameter that allowed differentiating the quality of the product. The baked products made with soft wheat flour had lower values of crumb firmness than products with hard wheat flour samples (Fig. 1), revealing a softer structure. The same tendency was observed for the crust firmness (Fig. $1)$, where all the products of hard wheat samples, except sample 6, had tougher crusts. The baked products from soft wheat flour seemed to have a more spongy structure, while hard wheat flour products had a firm arrangement associated with a previously layered structuration of the dough sheets.

\section{Relationships between flour characteristics, dough and yeast-leavened laminated product properties and quality}

Glutenin macropolymer content and dodecyl sulphate sedimentation volume of the flour samples showed associations with dough viscosity $(R=0.77$ and 0.79 , respectively; $\mathrm{p} \leq 0.05)$ and resistance to deformation $(\mathrm{R}=0.70$ and $\mathrm{R}=0.77$, respectively; $\mathrm{p} \leq 0.05$ ). The hard wheat flour samples with a high quality gluten network produced hard sheeted dough with a more solid-like behaviour and

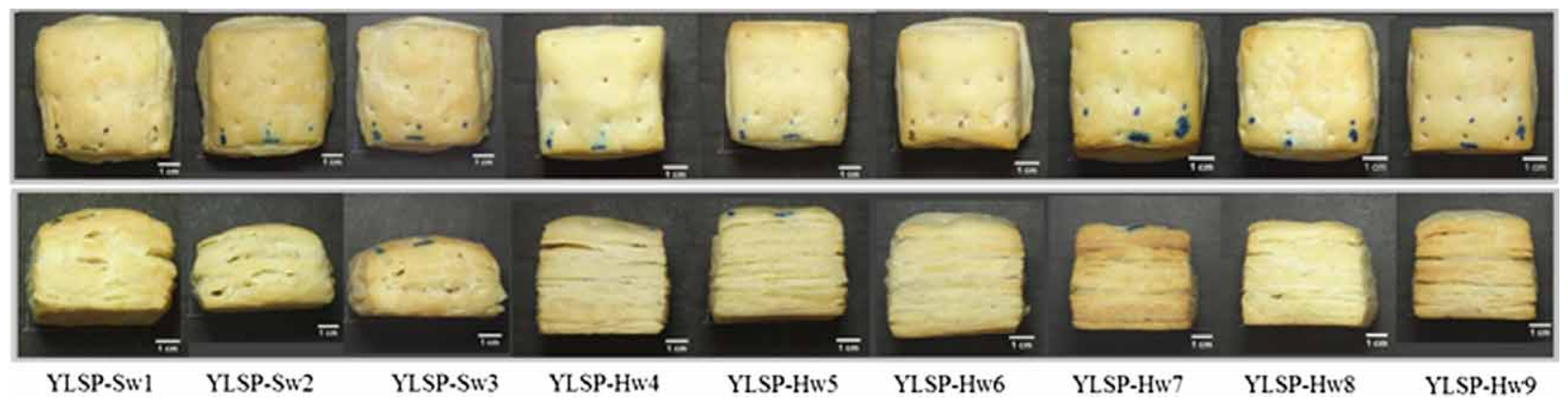

Fig. 2. Yeast-leavened laminated salty products (YLSP) made from soft wheat (Sw) flour and hard wheat (Hw) flour samples 
Table 3. Yeast-leavened laminated salty product quality parameters

\begin{tabular}{ccccc}
\hline Sample & $v /\left(\mathrm{g} / \mathrm{cm}^{3}\right)$ & $\mathrm{W}$ & $\mathrm{H}$ & $\mathrm{SF}$ \\
\hline Sw1 & $(3.7 \pm 0.2)^{\mathrm{a}}$ & $(1.11 \pm 0.02)^{\mathrm{b}}$ & $(2.3 \pm 0.3)^{\mathrm{a}}$ & $(0.6 \pm 0.1)^{\mathrm{a}}$ \\
Sw2 & $(3.2 \pm 0.1)^{\mathrm{a}}$ & $(1.15 \pm 0.07)^{\mathrm{b}}$ & $(2.3 \pm 0.1)^{\mathrm{a}}$ & $(0.54 \pm 0.04)^{\mathrm{a}}$ \\
Sw3 & $(2.7 \pm 0.1)^{\mathrm{a}}$ & $(1.14 \pm 0.04)^{\mathrm{b}}$ & $(2.3 \pm 0.2)^{\mathrm{a}}$ & $(0.52 \pm 0.06)^{\mathrm{a}}$ \\
Hw4 & $(3.4 \pm 0.3)^{\mathrm{a}}$ & $(1.02 \pm 0.03)^{\mathrm{a}}$ & $(2.8 \pm 0.3)^{\mathrm{b}}$ & $(0.7 \pm 0.1)^{\mathrm{b}}$ \\
Hw5 & $(3.12 \pm 0.08)^{\mathrm{a}}$ & $(1.02 \pm 0.03)^{\mathrm{a}}$ & $(2.80 \pm 0.05)^{\mathrm{b}}$ & $(0.81 \pm 0.02)^{\mathrm{b}}$ \\
Hw6 & $(4.0 \pm 0.8)^{\mathrm{b}}$ & $(1.05 \pm 0.01)^{\mathrm{a}}$ & $(2.6 \pm 0.2)^{\mathrm{a}}$ & $(0.77 \pm 0.02)^{\mathrm{b}}$ \\
Hw7 & $(3.48 \pm 0.08)^{\mathrm{a}}$ & $(1.00 \pm 0.02)^{\mathrm{a}}$ & $(2.4 \pm 0.3)^{\mathrm{a}}$ & $(0.75 \pm 0.08)^{\mathrm{b}}$ \\
Hw8 & $(3.62 \pm 0.01)^{\mathrm{a}}$ & $(1.1 \pm 0.0)^{\mathrm{a}}$ & $(2.57 \pm 0.01)^{\mathrm{a}}$ & $(0.8 \pm 0.0)^{\mathrm{b}}$ \\
Hw9 & $(3.3 \pm 0.3)^{\mathrm{a}}$ & $(1.01 \pm 0.01)^{\mathrm{a}}$ & $(2.5 \pm 0.2)^{\mathrm{a}}$ & $(0.77 \pm 0.06)^{\mathrm{b}}$ \\
\hline
\end{tabular}

$\mathrm{Sw}=$ product made with soft wheat flour, $\mathrm{Hw}=$ product made with hard wheat flour, $v=$ specific volume, $\mathrm{W}=$ width ratio, $\mathrm{H}=$ height ratio, $\mathrm{SF}=$ shape factor. Determinations were done at least in duplicate. Values followed by a different letter are significantly different $(\mathrm{p} \leq 0.05)$

less capable of flowing. Protein content of the flour was significantly and negatively correlated with width ratio and the shape factor $(R=-0.50$ and -51 , respectively; $\mathrm{p} \leq 0.05)$ of the baked products, while the wet gluten was only negatively associated with the width ratio $(\mathrm{R}=-0.47$; $\mathrm{p} \leq 0.05)$. There were significantly positive correlations between the glutenin macropolymer content and height ratio and the shape factor ( $R=0.55$ and 0.78 , respectively; $\mathrm{p} \leq 0.05)$, and a negative correlation with the width ratio $(R=-0.69 ; p \leq 0.05)$. This indicated that the flour high in glutenin macropolymer content produced laminated products which rise during the baking process and suffer less lateral expansions. Hay (6) found a positive correlation between flour protein, high molecular mass glutenin subunit and low molecular mass glutenin subunit content and the specific pastry height in puff pastry products without yeast leavening.

Predictive tests showed significant associations between the flour quality and the dimensional parameters of the products. The lactic acid SRC had positive correlations with the height ratio and the shape factor $(R=0.59$ and 0.63 , respectively; $\mathrm{p} \leq 0.05)$ and a negative correlation with the width ratio $(\mathrm{R}=-0.46, \mathrm{p} \leq 0.05)$. The sodium dodecyl sulphate sedimentation volume had positive correlations with the height ratio and the shape factor $(R=0.60$ and 0.79 , respectively; $\mathrm{p} \leq 0.05)$, and a negative correlation with the width ratio $(\mathrm{R}=-0.46, \mathrm{p} \leq 0.05)$. Results show that the expansion seems to be more related to the quality of protein and gluten than to their quantity.
In dough with added fat, fat competes with the aqueous phase for the surface of flour particles during dough mixing (29). The added shortening causes a lipid plasticisation of gluten and modifies or competes with the interactions of endogenous components. In the dough with high fat content (more than $5 \%$ ), the added fat appears to saturate the system and only part of the added lipid can exert a plasticising effect (30). One portion of the incorporated water will be an integral part of the dough and another will act as a plasticiser. The extent to which the water fulfills either role will depend on the presence of certain water-absorbing components, such as proteins, arabinoxylans and damaged starch. When the dough is subjected to compression, the mobility of water molecules present in the interparticle space influences the relaxation of dough. In the same way, in a layered structure system with thin fat/dough layers the fat would have a strong influence on the stress relaxation. Sodium carbonate SRC and water SRC showed significant associations with dough viscosity $(R=0.71$ and 0.80 , respectively; $p \leq 0.05)$ and resistance to deformation ( $\mathrm{R}=0.77$ and 0.81 , respectively; $\mathrm{p} \leq 0.05)$. These relationships suggest that in dough made with flour high in hydrophilic components, water mobility is limited. Water exerts a plasticiser effect and dough presents a strong cohesive structure with a higher value of $\eta$ (31). The correlations between dough resistance to deformation and the width ratio $(\mathrm{R}=-0.77 ; \mathrm{p} \leq 0.05)$ and the shape factor $(\mathrm{R}=0.70 ; \mathrm{p} \leq 0.05)$ of the yeast-leavened laminated products revealed that hard wheat dough samples may have a more rigid structure than soft wheat dough pieces. Therefore, dough samples made with hard wheat flour have a great capacity to form layers that can be vertically expanded. Shape factor showed positive correlations with the flour capacity to absorb water $(\mathrm{R}=0.83$; $\mathrm{p} \leq 0.05)$, sucrose $(\mathrm{R}=0.83 ; \mathrm{p} \leq 0.05)$ and sodium carbonate $(\mathrm{R}=0.83 ; \mathrm{p} \leq 0.05)$ and with dough viscosity $(\mathrm{R}=0.73 ; \mathrm{p} \leq 0.05)$. This revealed that the existence of a certain level of arabinoxylans and damaged starch generated viscous dough, which had a positive effect on the desirable expansion of the product. There were negative correlations between the width ratio and the sucrose SRC $(\mathrm{R}=-0.74 ; \mathrm{p} \leq 0.05)$ and sodium carbonate SRC $(\mathrm{R}=-0.78 ; \mathrm{p} \leq 0.05)$ of flour and dough viscosity $(\mathrm{R}=-0.79 ; \mathrm{p} \leq 0.05)$. These showed that undesirable increments of the width of the dough samples are related to less viscous dough samples, such as those made with soft wheat flour, which had a low content of components capable of holding water.

The following variables were simultaneously analyzed by MANOVA (Table 4): glutenin macropolymer content, lactic acid SRC and sodium carbonate SRC, viscosity, resistance to deformation, width ratio and shape

Table 4. The results of MANOVA analysis

\begin{tabular}{|c|c|c|c|c|c|c|c|c|c|}
\hline \multirow{2}{*}{ Sample } & \multirow{2}{*}{$w(\mathrm{GMP}) / \%$} & \multicolumn{3}{|c|}{$\mathrm{SRC} / \%$} & \multirow{2}{*}{$\eta /(\mathrm{kPa} \cdot \mathrm{s})$} & \multirow{2}{*}{$\mathrm{DR} / \mathrm{N}$} & \multirow{2}{*}{ W } & \multirow{2}{*}{ SF } & \multirow{2}{*}{ MANOVA } \\
\hline & & Lactic acid & Sucrose & Sodium carbonate & & & & & \\
\hline Sw & 2.16 & 94.53 & 71.92 & 72.65 & 107.91 & 658.45 & 1.13 & 0.56 & $\mathrm{a}$ \\
\hline $\mathrm{Hw}$ & 3.73 & 123.32 & 92.84 & 85.34 & 207.96 & 2150.91 & 1.03 & 0.77 & $\mathrm{~b}$ \\
\hline
\end{tabular}

$\mathrm{Sw}=$ soft wheat flour sample, $\mathrm{Hw}=$ hard wheat flour sample, GMP=glutenin macropolymer, $\mathrm{SRC}=$ solvent retention capacity, $\eta=$ viscosity, $\mathrm{DR}=$ dough resistance to deformation, $\mathrm{W}=$ width ratio, $\mathrm{SF}=$ shape factor. Different letters within a sample indicate significant differences $(p<0.05)$ between the groups of samples considering the eight variables at the same time 
factor. Flour samples, dough samples and yeast-leavened laminated products from hard wheat were significantly different from those from soft wheat. Hard wheat flour samples showed a good quality gluten network with high glutenin macropolymer content and lactic acid SRC values. Hard wheat flour had higher sucrose SRC and sodium carbonate SRC values than soft wheat flour, related to the greater amount of hydrophilic components. Dough samples showed a different behaviour when subjected to compression and during the stress relaxation process. Dough samples from hard wheat flour were more viscous and harder than those from soft wheat flour. The differences in flour and dough characteristics have an effect on the properties of yeast-leavened laminated products. Products from hard wheat flour samples had a higher shape factor and lower width ratio than products from soft wheat flour. These results are in agreement with Manley's (29) observations, since he mentioned that laminated dough relaxation periods are related to the length and shape of the baked product. The combined use of the selected variables related to flour, dough and product characteristics allowed to differentiate among wheat flour samples with different suitability to produce yeast-leavened laminated products.

\section{Conclusions}

Flour quality and dough parameters that help to predict the quality of a yeast-leavened laminated salty product were established. A flour sample with high glutenin macropolymer content, a strong glutenin network, and a certain level of hydrophilic components is suitable for the production of viscous dough with high resistance to deformation and, consequently, a laminated baked product with an optimum quality, which rises and does not lose the expected shape.

The components present in the flour and later in the dough have an influence on the final quality of the laminated baked products. Hydrophilic components which can hold water generated a rigid structure and viscous dough. The gluten network quality influenced, to a lesser extent, dough firmness. Dough samples with a more viscous behaviour suffered a lift rather than a lateral expansion, without losing the expected shape, when exposed to heat during baking. Hard wheat flour samples were significantly different from soft wheat flour samples. Laminated baked products from hard wheat flour had better quality properties than those from soft wheat flour, revealing that flour from hard wheat is more suitable for making this kind of product.

\section{Acknowledgements}

The authors would like to thank the Secretary of Science and Technology of National University of Cordoba, Argentina (SECyT-UNC), for financial support. Also, the authors would like to thank Gabriela Diaz Cortes, for her spelling check of the manuscript.

\section{References}

1. O'Brien RD. Baking shortenings. In: $\mathrm{O}^{\prime}$ Brien $\mathrm{RD}$, editor. Fats and oils: formulating and processing for applications. Boca Raton, FL, USA: CRC Press; 2004. pp 145-62.
2. Cauvain S, Young L. Laminated products. In: Cauvain $S$, Young L, editors. Baking problems solved. Abington, Cambridge, UK: Woodhead Publishing Limited; 2001. pp. 124-35. http://dx.doi.org/10.1533/9781855736184.124

3. Matzs SA. Formulas and processes. In: Matzs SA, editor. Bakery technology and engineering. McAllen, TX, USA: Pan-Tech International, Inc.; 1999. pp. 251-500.

4. Davies AP, Patient DW, Ingman SJ, Ablet S, Drage M, Asquith M, Barnes DJ. Wheat protein properties and puff pastry structure. In: Lásztity R, Bekes F, editors. Proceedings of the Third International Workshop on Gluten Proteins; 1987 May 9-12; Budapest, Hungary: World Scientific Publishing Co.; 1987. pp. 466-77.

5. Zabik ME, Tipton RC. Pie crust quality: influence of use of fractionated and reconstituted soft wheat flour of varied protein content. Cereal Chem. 1989;66:313-17.

6. Hay RL. Effect of flour quality characteristics on puff pastry baking performance. Cereal Chem 1993;70:392-6.

7. Geittner J. L-Cysteine for the simplification of the manufacture of biscuits and puff pastry. Getreide Mehl Brot. 1978;32: 124-6.

8. Morgenstern MP, Newberry MP, Holst SE. Extensional properties of dough sheets. Cereal Chem. 1996;73:478-82. http://dx.doi.org/C-1996-0606-01R

9. Giannoni W. History with new strategy. Córdoba, Argentina: Diario La Voz del Interior [Internet]. 2012. Available from: http://www.lavoz.com.ar/cordoba/historia-con-nueva-estrategia (in Spanish).

10. AACC International Method 46-10.01. Crude protein-improved Kjeldahl method. St. Paul, MN, USA: American Association of Cereal Chemists (AACC) International; 2000.

11. AACC International Method 38-10.01. Gluten - hand washing method. St. Paul, MN, USA: American Association of Cereal Chemists (AACC) International; 2000.

12. Don C, Lichtendonk W, Plijter JJ, Hamer RJ. Glutenin macropolymer: a gel formed by glutenin particles. J Cereal Sci. 2003;37:1-7.

http://dx.doi.org/10.1006/jcrs.2002.0481.

13. AACC International Method 46-13.01. Crude protein - micro-Kjeldahl method. St. Paul, MN, USA: American Association of Cereal Chemists (AACC) International; 2000.

14. AACC International Method 56-11.02. Solvent retention capacity profile. St. Paul, MN, USA: American Association of Cereal Chemists (AACC) International; 2000.

15. AACC International Method 56-70.01. Sodium dodecyl sulfate sedimentation test for durum wheat. St. Paul, MN, USA: American Association of Cereal Chemists (AACC) International; 2000.

16. Viscoelasticity. In: Steffe JF, editor. Rheological methods in food process engineering. East Lansing MI, USA: Freeman Press; 1996. pp. 294-349.

17. Di Rienzo JA, Guzmán AW, Casanoves F. A multiple comparisons method based on the distribution of the root node distance of a binary tree. J Agric Biol Environ Stat. 2002;7:129-42.

http://dx.doi.org/10.1198/10857110260141193

18. Sliwinsky EL, Kolster P, van Vliet T. On the relationship between large-deformation properties of wheat flour dough and baking quality. J Cereal Sci. 2004;39:231-45. http://dx.doi.org/10.1016/j.jcs.2003.10.005

19. Don C, Mann G, Bekes F, Hamer RJ. HMW-GS affect the properties of glutenin particles in GMP and thus flour quality. J Cereal Sci. 2006;44:127-36. http://dx.doi.org/10.1016/j.jcs.2006.02.005

20. Steffolani ME, Pérez GT, Ribotta PD, León AE. Relationship between variety classification and breadmaking quality in 
Argentine wheats. Int J Agric Res. 2007;2:33-42.

http://dx.doi.org/10.3923/ijar.2007.33.42

21. Gaines CS. Collaborative study of methods for solvent retention capacity profiles (AACC method 56-11). Cereal Food World 2000; 45: 303-6.

22. Moiraghi M, Ribotta PD, Aguirre AV, Pérez GT, León AE. Study of hard wheat flour quality in cookie and sponge cake elaboration. Agriscientia. 2005;22:47-54 (in Spanish).

23. Colombo A, Pérez GT, Ribotta PD, León AE. A comparative study of physicochemical tests for quality prediction of Argentine wheat flours used as corrector flours and for cookie production. J Cereal Sci. 2008;48:775-80. http://dx.doi.org/10.1016/j.jcs.2008.05.003

24. Xiao ZS, Park SH, Chung OK, Caley MS, Seib PA. Solvent retention capacity values in relation to hard winter wheat and flour properties and straight-dough breadmaking quality. Cereal Chem. 2006;83:465-71. http://dx.doi.org/10.1094/CC-83-0465

25. Moiraghi M, Vanzetti L, Bainotti C, Helguera M, León A, Pérez G. Relationship between soft wheat flour physicochemical composition and cookie-making performance. Cereal Chem. 2011;88:130-6. http://dx.doi.org/10.1094/CCHEM-09-10-0131

26. Peleg M. The basics of solid food rheology. In: Moskowitz $\mathrm{HR}$, editor. Food texture: instrumental and sensory measure- ment. New York, NY, USA: Marcel Dekker Inc.; 1987. pp. 3-34.

27. Rao VK, Mulvaney SJ, Dexter JE, Edwards NM, Peressini D. Stress-relaxation properties of mixograph semolina-water doughs from durum wheat cultivars of variable strength in relation to mixing characteristics, bread- and pasta-making performance. J Cereal Sci. 2001;34:215-32. http://dx.doi.org/10.1006/jcrs.2001.0384

28. Li W, Dobraszczyk BJ, Schofield JD. Stress relaxation behavior of wheat dough, gluten, and gluten protein fractions. Cereal Chem. 2003;80:333-8. http://dx.doi.org/C-2003-0416-03R

29. Manley DJ. Classification of biscuits. In: Manley DJ, editor. Technology of biscuits, crackers, and cookies. Abingdon, Cambridge, UK: Woodhead Publishing Limited; 2000. pp. 221-8. http://dx.doi.org/10.1533/9781855736597.3.221

30. Fu J, Mulvaney SJ, Cohen C. Effect of added fat on the rheological properties of wheat flour doughs. Cereal Chem. 1997;74:304-11.

http://dx.doi.org/10.1094/CCHEM.1997.74.3.304

31. Bhattacharya S. Stress relaxation behaviour of moth bean flour dough: product characteristics and suitability of model. J Food Eng. 2010;97:539-46. http://dx.doi.org/10.1016/j.jfoodeng.2009.11.014 